without moderating our behavior, we will break this young allocation system quickly.

\section{References}

1. Estep JD, Soltesz E, Cogswell R. The new heart transplant system: early observations and mechanical circulatory support considerations. J Thorac Cardiovasc Surg. 2021;161:1839-46.

2. Nativi JN, Kfoury AG, Myrick C, Peters M, Renlund D, Gilbert EM, et al. Effects of the 2006 U.S. thoracic organ allocation change: analysis of local impact on organ procurement and heart transplantation. J Heart Lung Transplant. 2010;29:235-9.

3. Colvin M, Smith JM, Hadley N, Skeans MA, Carrico R, Uccellini K, et al. OPTN/ SRTR 2016 annual data report: heart. Am J Transplant. 2018;18(suppl 1):291-362.

4. Huckaby LV, Seese LM, Mathier MA, Hickey GW, Kilic A. Intra-aortic balloon pump bridging to heart transplantation: impact of the 2018 allocation change. Circ Heart Fail. 2020;13:e06971.

5. OPTN Thoracic Transplantation Committee One-Year Monitoring of Heart Allocation Proposal to Modify the Heart Allocation System. Available at: https://optn. transplant.hrsa.gov/media/3701/data_report_thoracic_committee_heart_ subcommittee_20200227_rpt1_revised_508_compliant.pdf. Accessed July 1, 2020 .

6. Ouyang D, Gulati G, Ha R, Banerjee D. Incidence of temporary mechanical circulatory support before heart transplantation and impact on post-transplant outcomes. J Heart Lung Transplant. 2018;37:1060-6.

7. OPTN, Guidance and Policy Clarifications Addressing Adult Heart Allocation Policy Available at: https://optn.transplant.hrsa.gov/media/3931/guidance_poli cy_clarifications_address_adult_heart_allocation_policy.pdf. Accessed August 15, 2020.

8. Yin MY, Wever-Pinzon O, Mehra M, Selzman CH, Toll AE, Cherikh WS, et al. Post-transplant outcome in patients bridged to transplant with temporary mechanical circulatory support devices. J Heart Lung Transplant. 2019;38:858-69.

9. Jasseron C, Lebreton G, Cantrelle C, Legeai C, Leprince P, Flecher E, et al. Impact of heart transplantation on survival in patients on venoarterial extracorporeal membrane oxygenation at listing in France. Transplantation. 2016;100:1979-87.

10. Varshney AS, Berg DD, Katz JN, Baird-Zars VM, Erin A, Bohula EA, et al. Use of temporary mechanical circulatory support for management of cardiogenic shock before and after the united network for organ sharing donor heart allocation system changes. JAMA Cardiol. 2020;5:703-8.

\section{Commentary: Flying too close to}

\section{the sun}

\author{
Anh-Thu Le, MD, and Nahush A. Mokadam, MD
}

There is a well-known Greek myth in which the architect Daedalus crafts a pair of wax and feather wings to escape the clutches of the cruel King of Crete. Daedalus wishes to free his son Icarus first, and launches him away after warning his only child to not fly too high, as the sun's rays would melt the waxy wings. Alas, Icarus, young and eager, falls to his death after disregarding his father's admonition. ${ }^{1}$ While it is only an ancient story, it does still have relevance in the world of heart transplantation. Each year, more patients are listed for heart transplant whereas the number of donor hearts remains impertinently stagnant. ${ }^{2}$ Like the old inventor wanting to

From the Division of Cardiac Surgery, The Ohio State University Wexner Medical Center, Columbus, Ohio.

Disclosures: Dr Mokadam is a consultant for Medtronic, Abbott, SynCardia, and Carmat. Dr Le has reported no conflicts of interest.

The Journal policy requires editors and reviewers to disclose conflicts of interest and to decline handling or reviewing manuscripts for which they may have a conflict of interest. The editors and reviewers of this article have no conflicts of interest

Received for publication Sept 5, 2020; revisions received Sept 5, 2020; accepted for publication Sept 8, 2020; available ahead of print Sept 12, 2020.

Address for reprints: Nahush A. Mokadam, MD, Division of Cardiac Surgery, The Ohio State University, Columbus, OH 77030 (E-mail: Nahush.Mokadam@ osumc.edu).

J Thorac Cardiovasc Surg 2021;161:1848-9

$0022-5223 / \$ 36.00$

Copyright (c) 2020 by The American Association for Thoracic Surgery

http://dx.doi.org/10.1016/j.jtcvs.2020.09.028

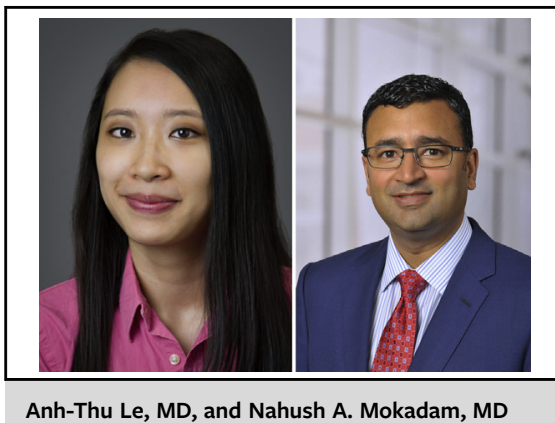

Anh-Thu Le, MD, and Nahush A. Mokadam, MD

CENTRAL MESSAGE

We must continue to optimize organ allocation with ongoing evaluation and modification of existing systems. Undoubtedly, this will cause some unanticipated outcomes that require vigilance.

save his son, we want to save our patients by transplanting as many donor hearts as we can to those who will benefit most.

In this issue of the Journal, Estep and colleagues ${ }^{3}$ discuss the outcomes on heart transplantation after the implementation of new adult heart allocation guidelines in October of 2018. There were changes for the better: for example, more patients received heart transplants after implementation of the guidelines, there were no changes to mortality over 180 days for patients who were listed, and the available donor network 
seemed to have widened, based on the increase in median travel distance for the donor hearts. ${ }^{4}$ However, there were also some findings that do give one pause and are worth addressing. Of the 124 transplanting centers examined, a little less than half performed fewer transplantations after the new allocation guidelines were implemented. Although there seems to be a wider area of distribution for these donor hearts, that distance comes with a price-a statistically significant increase in ischemic time, which may in part explain why the 180-day post-transplant mortality was also greater for patients after the update to the guidelines. By continuing to transplant patients after the allocation changes, whether due to lack of resources, increased donor ischemic time, or other intangibles, have some of these centers flown too closely to the sun?

It is important, as the authors themselves note, that some of the data was acquired early after October 2018, and there may not have been a sufficient sample size to draw any firm conclusions about the updated allocation system. Changes made by the United Network for Organ Sharing result in more donor organs-but we would do well to remember that there may be some unintended negative consequences, as there were for the listed status 2 patients after the 1999 United Network for Organ Sharing change to the allocation scheme. ${ }^{5}$ What also, of the 56 programs whose transplant volumes decreased after the change to the allocation system? Centralization of care may have some advantages but may also limit access to patients who are unable to travel. Myths are still told even thousands of years later because the lessons they impart are still relevant to us today. Let us continue to pursue changes to the allocation system, let us continue to maximize the hearts transplanted. We must continue to study the outcomes of the patients transplanted after the update and use the sturdy wings of knowledge to safely propel all transplant centers and our patients forward. Let us do better than Daedalus!

\section{References}

1. Hamilton E. Mythology. New York: Back Bay Books/Little, Brown and Company; 2013:192-4.

2. Colvin-Adams M, Smithy J, Skeans MA, Edwards LB, Callahan ER, Snyder JJ et al. OPTN/SRTR 2014 Annual data report: heart. Am J Transplant. 2016; 16(Suppl 2):115-40

3. Estep JD, Soltesz E, Cogswell R. The new heart transplant allocation system: early observations and mechanical circulatory support considerations. J Thorac Cardiovasc Surg. 2021;161:1839-46.

4. Cogswell R, John R, Estep JD, Duval S, Tedford RJ, Pagani FD, et al. An early investigation of outcomes with the new 2018 donor heart allocation system in the United States. J Heart Lung Transplant. 2020;39:1-4

5. Mokadam NA, Ewald GA, Damiano RJ Jr, Moazami N. Deterioration and mortality among patients with United Network for Organ Sharing status 2 heart disease: caution must be exercised in diverting organs. J Thorac Cardiovasc Surg. 2006;131:925-6.

\title{
Commentary: The ethics of donor allocation
}

\author{
Vivek Rao, MD, $\mathrm{PhD}$
}

Cardiac transplantation involves major ethical dilemmas at all stages of the transplant process. In contrast to liver and kidney donors, an increasing proportion of whom are living-related, heart donors are primarily young individuals

\footnotetext{
From the Cardiovascular Surgery, Peter Munk Cardiac Centre, Toronto General Hospital, Toronto, Ontario, Canada.

Disclosures: The author reported no conflicts of interest.

The Journal policy requires editors and reviewers to disclose conflicts of interest and to decline handling or reviewing manuscripts for which they may have a conflict of interest. The editors and reviewers of this article have no conflicts of interest.

Received for publication Sept 21, 2020; revisions received Sept 21, 2020; accepted for publication Sept 23, 2020; available ahead of print Sept 28, 2020.

Address for reprints: Vivek Rao, MD, PhD, Cardiovascular Surgery, Peter Munk Cardiac Centre, Toronto General Hospital, 200 Elizabeth St, Toronto, Ontario, Canada M5G2C4 (E-mail: vivek.rao@uhn.ca).

J Thorac Cardiovasc Surg 2021;161:1849-51

$0022-5223 / \$ 36.00$

Copyright (c) 2020 by The American Association for Thoracic Surgery

http://dx.doi.org/10.1016/j.jtcvs.2020.09.088
}

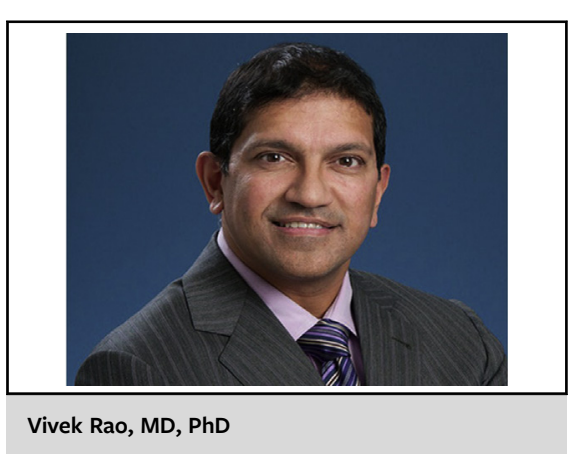

CENTRAL MESSAGE

All aspects of cardiac transplan-

tation involve important ethical considerations. Changes to any of these aspects demand careful consideration and constant evaluation of their impact. 